\title{
Using Regression Trees to Find the Factors Influencing the Level of Knowledge about Fertility and the Diet That Supports It among People Dancing in Max Dance Studio in Białystok
}

\author{
Adrianna Zańko ${ }^{1}$, Karolina Milewska ${ }^{2}$, Marcin Warpechowski ${ }^{3}$, \\ Robert Milewski ${ }^{3}$ \\ 1 Doctoral Studies, Medical University of Bialystok, Poland \\ 2 Student Research Group at the Department of Statistics and Medical Informatics, \\ Medical University of Bialystok, Poland \\ 3 Department of Statistics and Medical Informatics, Medical University of Bialystok, \\ Poland
}

\begin{abstract}
Many studies confirm the fact that women do not have sufficient knowledge about reproductive health, which is a significant problem nowadays due to the large percentage of people who suffer from infertility. A sources of knowledge from which information about health, including reproductive health, is obtained have various levels of reliability. The aim of the study was to use regression trees to find which of the analysed parameters had the greatest impact on the level of respondents' knowledge about fertility and the impact of diet on fertility. The study was conducted among women who practice dance in Max Dance studio in Białystok. The group consisted of 42 women with an average age of 26.3 years, dancing in various dance styles at various levels of proficiency. A questionnaire on lifestyle and a sources of information on fertility was used; the questionnaire also contained a knowledge test focused on reproductive health and the impact of diet on fertility, in which the questions were based on information from the latest research. Three regression trees were created for three indicators determining the level of respondents' knowledge. The obtained results revealed certain areas that have a significant impact on the level of knowledge about reproductive health, which may require additional education. The use of the regression trees method made it possible to determine the relationships between the analysed data that were not fully visible after standard biostatistical analyses had been performed. The created trees can be useful in improving the process of disseminating knowledge about reproductive health among women of childbearing age.
\end{abstract}

\section{Introduction}

Free access to the Internet has changed the world and its functioning. The Internet is one of the places from which information is obtained, 
which is not always adequate or confirmed. When looking for information about their health condition, many people start their search from the Internet. Doubtlessly, the Internet is not the most reliable place to look for a diagnosis or medical knowledge as the straightforward character of the process of placing entries online is associated with a huge amount of false information that a patient seeking help may find. When it comes to knowledge about fertility, research results confirm that one of the main sources of knowledge about fertility among young people is the Internet, and less than $30 \%$ of people interested in the topic seek professional knowledge from a doctor.

Lifestyle, including diet, has a significant impact on human fertility (Skoracka et al., 2021). The products consumed daily are a source of vitamins and minerals, as well as anti-nutritional substances. Another aspect important in the context of reproductive health is the nutritional status as malnutrition, just as excessive body weight, can cause problems with becoming pregnant (Becker et al., 2015; Gambineri et al., 2019; Suliga \& Głuszek, 2019). A set of basic principles concerning a diet that should be beneficial for fertility exists, but ultimately each person is different, so a perfectly matched menu should be determined individually (Skoracka et al., 2021). With certain medical conditions, diet is an element that determines whether a woman can get pregnant or not. Such diet-related diseases related to fertility include: Polycystic Ovary Syndrome (PCOS), diabetes, insulin resistance, obesity, hypothyroidism, or inflammatory bowel diseases (Becker et al., 2015; Gambineri et al., 2019; Maliszewska et al., 2017; Zawiejska et al., 2016). In each of these diseases, different types of food are considered as "nutrition for fertility"; hence, it is very important that information on how to improve a person's reproductive health should be obtained from a reliable and proven source.

Unreliable knowledge about health, including reproductive health, can have negative consequences. Misdiagnoses may lead to unnecessary selftreatment, which can harm rather than help. Additionally, misinformation sourced from the Internet can give false hope or deepen the anxiety about the health situation of the person seeking information. Another aspect is financial, i.e. when deciding on an unproven therapy, research or supplements, a significant amount of money is often spent, which can exacerbate frustration, leading to neglecting the care of one's own health (Ilic, 2010).

What young scientists learn is how to look for reliable information; unfortunately, the majority of society rarely knows where to find it, has no access to it, or does not understand the content as it is written in a language 
typical for science. Certain questions are thus necessary: What means do people usually use in the context of obtaining information on fertility? How does this relate to their level of knowledge? What can be done to make sure that the information received is accurate?

The aim of the study was to use regression trees to find which of the analysed parameters had the greatest impact on the level of the respondents' knowledge about fertility and the impact of diet on fertility.

\section{Materials and Methods}

The study was conducted among women who practice dance in Max Dance studio in Białystok. The group consisted of 42 women with an average age of 26.3 years, dancing in various dance styles at various levels of proficiency.

In order to obtain information concerning the respondents' knowledge about fertility, fertility diet, and a source of knowledge from which they obtain information on a daily basis, a questionnaire on lifestyle was used, including components such as: physical activity, diet, perceived stress, and the quality of sleep. The survey also included a knowledge test on reproductive health and the effects of diet on fertility, in which the questions were based on information from the latest research.

The statistical analysis included the data for 43 women dancing in Max Dance studio in Białystok. A knowledge test was performed in two categories: general knowledge about fertility (a maximum of 6 points to be scored) and knowledge about fertility diet (a maximum of 10 points to be scored). A variable was also created that determines the general state of the respondents' knowledge about reproductive health, i.e. the sum of points scored in both tests (a maximum of 16 points to be scored). The following features were taken into account as independent variables that may have an impact on the results scored in the knowledge test:

- age

- BMI

- education (primary, secondary, higher)

- place of residence (village, town of up to 50,000 inhabitants, town of 50,000-100,000 inhabitants, town of more than 100,000 inhabitants)

- marital status (unmarried/no partner; unmarried/in a relationship; married)

- type of dance (multiple-choice question with the following possible answers: jazz, dancehall, burlesque, stretching - strings and twines, 
ballroom dancing, Pilates, Zumba, Broadway Jazz, twerk, sexy dance, Latino, discofox, belly dance)

- duration of classes

- level of proficiency of the classes (basic, intermediate, advanced)

- sleep duration

- participation in additional sports activities (answer yes/no)

- regularity of periods

- frequency and reasons for visits to the gynaecologist (I have never been; I have been to the gynaecologist once in my life; I visit, but only for a prescription; I go regularly and have tests)

- started having sexual intercourse

- suffering from premenstrual syndrome (PMS)

- feeling pain during periods

- presence of chronic diseases

- answer to the question "Do you pay attention to what you eat?"

- source of knowledge about fertility (multiple-choice question with the following possible answers: I am not interested in fertility, from the Internet, from friends, from mom/aunt/grandmother, etc., from a doctor, from a dietitian, from books/scientific journals)

- self-assessment in the topic of fertility on a scale of 1-10

- self-assessment in the topic of fertility diet on a scale of 1-10

Decision trees is a method supporting the decision-making process used, inter alia, in the decision theory. Decision tree algorithms can also be used in machine learning to obtain knowledge based on examples (Koronacki \& Ćwik, 2005). In the decision theory, a decision tree is a tree of decisions and their possible consequences. The purpose of using the method can be both to formulate a plan and to solve a decision problem. It is extremely useful in solving decision problems with branching variants and in situations of decision-making under high-risk conditions. Many algorithms exist whose aim is to predict the values of continuous or nominal variables from a set of predictors that are also continuous or nominal (Breiman et al., 1984).

A classification problem arises where there is a nominal dependent variable whose value is sought based on the known value of a number of continuous or nominal predictors. These are classification trees (Milewska et al., 2016), while in the case of regression trees, the value of a continuous variable is sought based on the known value of a certain number of continuous or nominal predictors (Gatnar, 2001). 


\section{Results and Discussion}

A maximum of 6 points could be scored in the general fertility test. A regression tree with 2 levels was created; at the first level the algorithm took into account the respondents' declaration of using books and scientific journals as a source of knowledge about fertility, while at the second level - results of the respondents' self-assessment in the above topic (Figure 1).

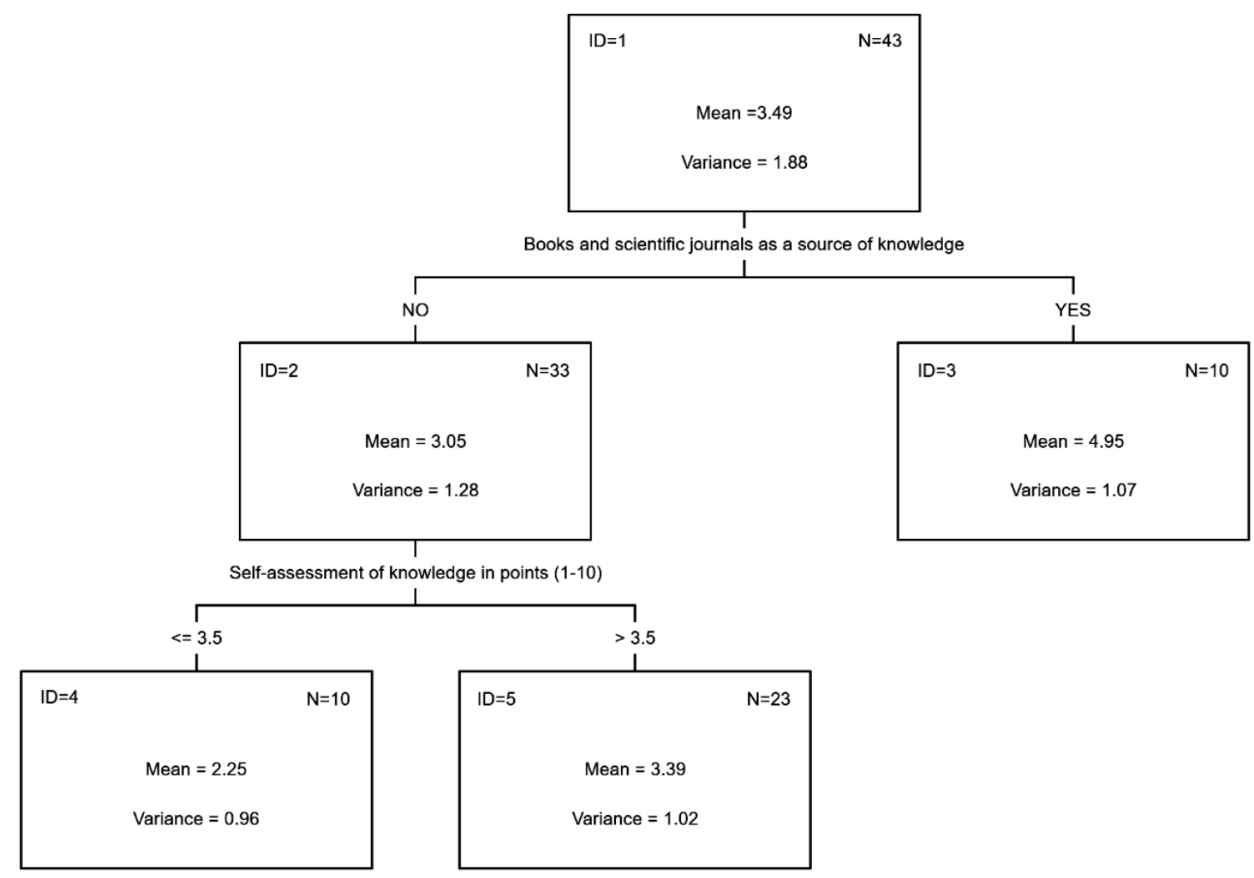

Figure 1. Regression tree for the number of points scored in the fertility knowledge test

At the first level, the algorithm placed a variable dividing the respondents into those who chose books and scientific journals $(\mathrm{n}=10)$ as a source of knowledge about fertility, and those who did not indicate this choice $(\mathrm{n}=33)$. The average number of points scored in the knowledge test in the group educated by books and scientific journals was Mean $=4.95$ points, while in the group that did not indicate this source, Mean $=3.05$ points. At the second level, the algorithm divided the group that did not use scientific books and journals according to their self-confidence regarding their general knowledge about fertility. The first cluster consisted of people who, on a scale from 1 to 10, rated their knowledge at a level of 0 to 3.5 points 
inclusive ( $\mathrm{n}=10)$, while the second group consisted of people who assigned themselves a rating of above 3.5 points $(\mathrm{n}=23)$. People who assessed their knowledge at a maximum of 3.5 points, inclusive, scored an average of Mean $=2.25$ points in the knowledge test, while those who rated their knowledge at more than 3.5 points scored an average of Mean $=3.39$ points in the knowledge test.

A maximum of 10 points could be scored in the fertility diet test. A three-level regression tree was created where, at the first level, the algorithm took into account the respondents' declaration of using books and scientific journals as a source of knowledge about fertility; at the second level - results of the respondents' self-assessment of the above topic; and on the third level - the respondents' declaration on the use of the Internet as a source of knowledge about fertility (Figure 2).

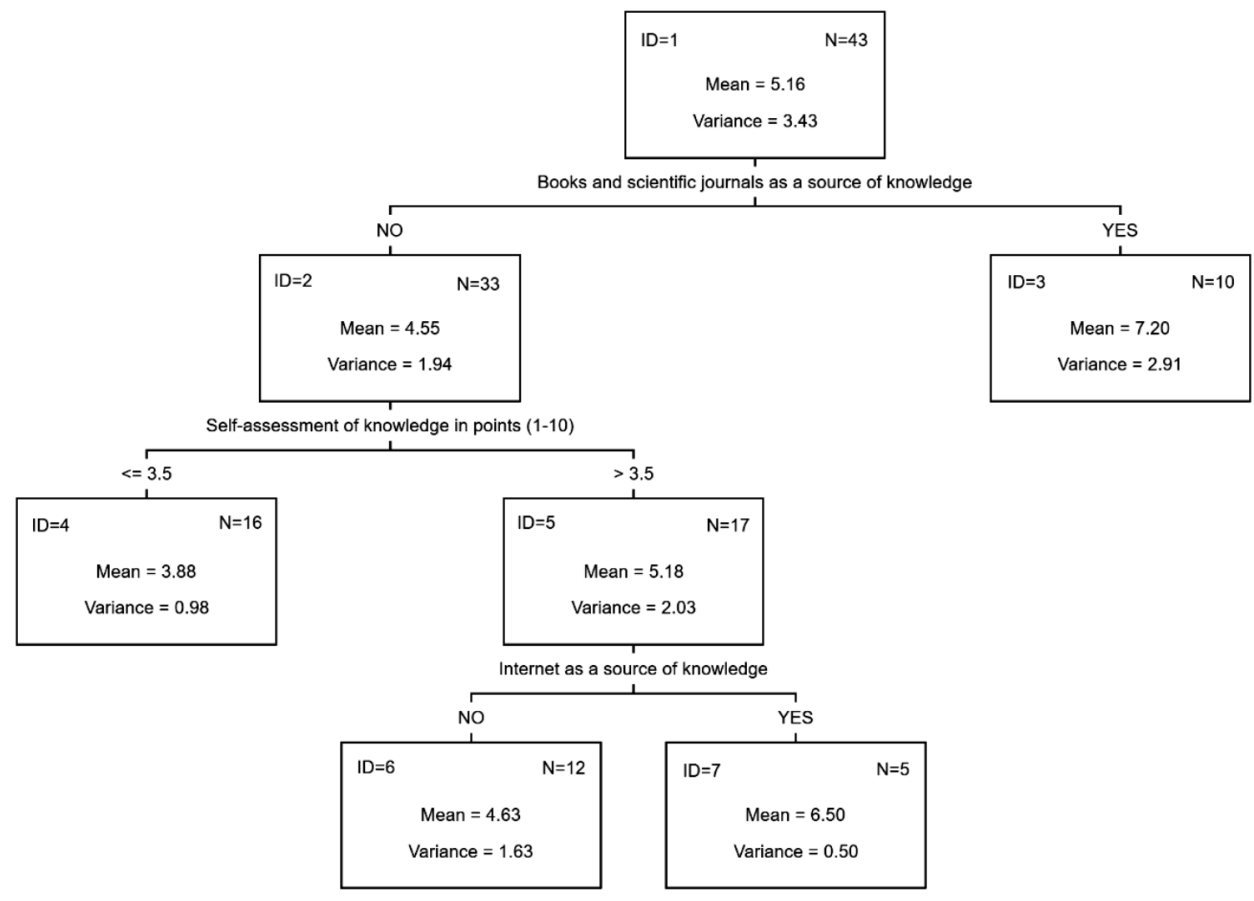

Figure 2. Regression tree for the number of points scored in the knowledge test on the relationship between diet and fertility

At the first level, the algorithm placed a variable dividing the respondents into those who chose books and scientific journals $(n=10)$ as a source of knowledge about fertility, and those who did not indicate such a choice $(\mathrm{n}=33)$. The average number of points scored in the knowledge test in the 
group educated by books and scientific journals was Mean $=7.20$ points, while in the group that did not indicate this source, Mean $=4.55$ points. At the second level, the algorithm divided the group that did not use scientific books and journals according to their self-confidence regarding their general knowledge about fertility diet. The first group consisted of people who, on a scale from 1 to 10, rated their knowledge at a level of 0 to 3.5 points inclusive $(\mathrm{n}=16)$, while the second group consisted of people who assigned themselves a rating of above 3.5 points $(n=17)$. People who assessed their knowledge at a maximum of 3.5 points, inclusive, scored an average of Mean $=3.88$ points in the knowledge test, while those who rated their knowledge at more than 3.5 points, scored an average of Mean $=5.18$ points in the knowledge test. At the third level, the algorithm divided the group that scored more than 3.5 points according to whether they used the Internet as a source of fertility knowledge or not. The first group consisted of people who used the Internet as a source of knowledge about fertility $(\mathrm{n}=5)$, while the second group consisted of people who did not use this source $(\mathrm{n}=12)$. People who used the Internet as a source of knowledge received an average of Mean $=6.50$ points in the knowledge test, while those who did not use this source received an average of Mean $=4.63$ points in the knowledge test.

A maximum of 16 points could be scored in the reproductive health test (fertility + diet). A two-level regression tree was created, where at the first level the algorithm took into account the respondents' declaration of using books and scientific journals as a source of knowledge about fertility; at the second level - age of the respondents was taken into consideration (Figure 3).

At the first level, the algorithm placed a variable dividing the respondents into those who chose books and scientific journals $(n=10)$ as a source of knowledge about fertility, and those who did not indicate such a choice $(n=33)$. The average number of points scored in the knowledge test in the group educated by books and scientific journals was Mean $=12.15$ points, while in the group that did not indicate this source, Mean $=7.59$ points. At the second level, the algorithm divided the group that did not use scientific books and journals depending on their age. The first group consisted of people who were 26.5 years old or younger $(\mathrm{n}=20)$, while the second group consisted of people over 26.5 years $(\mathrm{n}=13)$. People who were 26.5 years old or younger received an average of Mean $=6.80$ points in the knowledge test, while those who were over 26.5 years received an average of Mean $=8.81$ points in the knowledge test. 


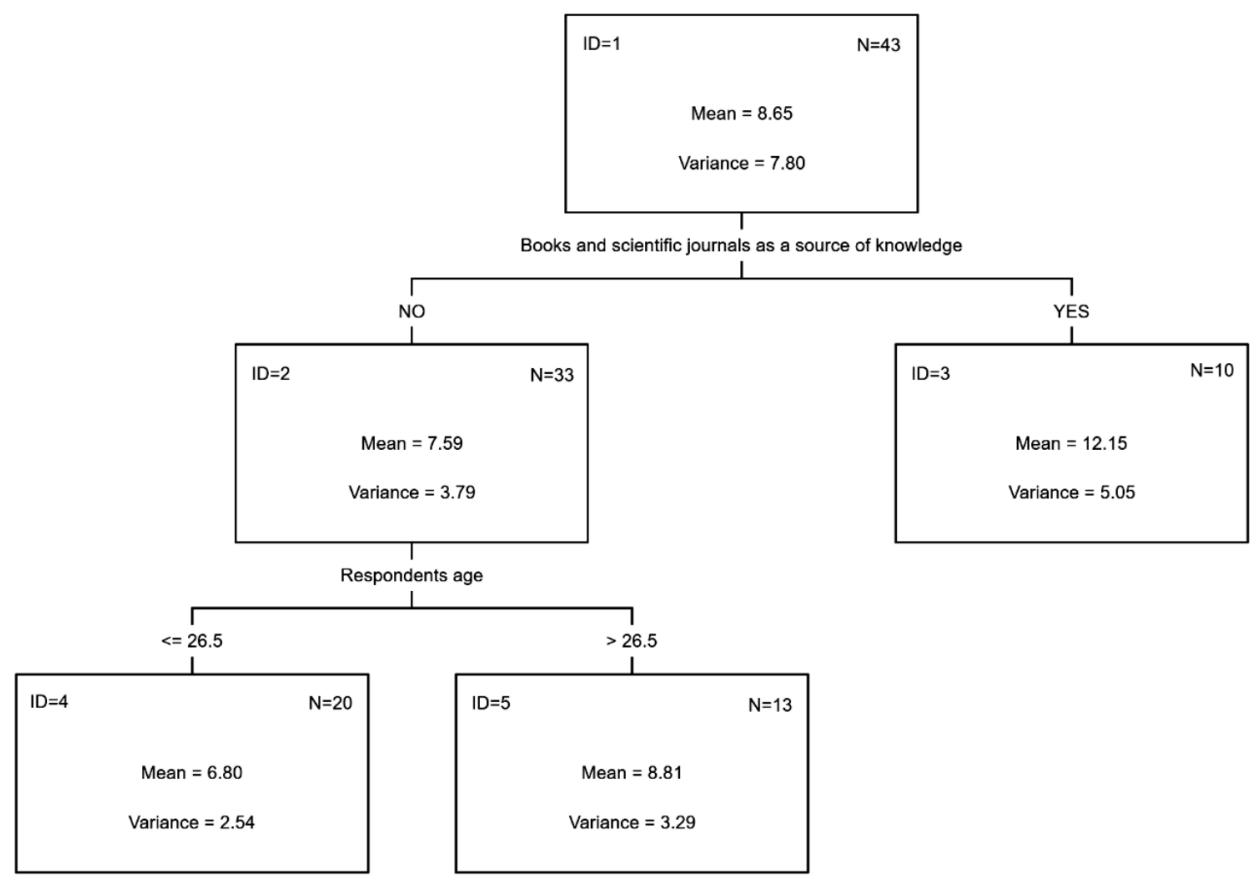

Figure 3. Regression tree for the sum of points scored in both tests

The level of knowledge about reproductive health among women of reproductive age is usually low (Chawłowska et al., 2020; Mu et al., 2019; Newton et al., 2020). Although Chawłowska et al. suggest that health care professionals are a reliable source of knowledge (Chawłowska et al., 2020), it turns out that even those women who obtain information in a doctor's office do not have adequate knowledge even about such basic topics as when the fertile window occurs (Hampton \& Mazza, 2015). This data is confirmed by the fact that the regression trees method used in this study did not recognize the group that obtained their knowledge in a doctor's office as one that scored a higher result in any of the knowledge tests. It is difficult to determine why this is so - information obtained in doctor's offices may be outdated (lack of specific courses), there may be no time for adequate patient education (too few specialists, too many patients), or there may be a lack of interest in fertility on the patient's part.

In this study, it was found out that women who based their knowledge on books/scientific journals scored the most points in all the tests. In a study by $\mathrm{Mu}$ et al., a higher level of knowledge about fertility was associated with a lower number of subjectively assessed risk factors for infertility-related diseases (Mu et al., 2019). Even though a study by Griffiths et al. (2019) 
states that the number of Open Access scientific articles is increasing, access to scientific articles for people who are not employees or students of medical universities is still limited (Griffiths et al., 2019). The main barriers for scientists to publish publicly have been the high fees and the low level of prestige of journals (O'Hanlon et al., 2020). In another study, conducted in 2020 by Jahn et al., scientists were shown to be apprehensive about sharing knowledge about public health, even among specialists, due to the fear that such a practice will scare off companies interested in developing new drugs (Jahn et al., 2020).

In each of the knowledge tests discussed in this study, the regression trees at the second level indicated that self-assessment of knowledge in a given area corresponded to the current level of knowledge. This does not always happen, as in many studies the respondents believe that their knowledge about fertility or a healthy diet is higher than it really is (Mu et al., 2019; Myszkowska-Raciak et al., 2013). The fact that among the surveyed women, the level of knowledge correlated with their selfconfidence in this area indicates that they are aware of their deficiencies and may be more willing to participate in education. This may have a positive impact on the implementation of possible activities related to the dissemination of knowledge about reproductive health and how lifestyle influences it.

Will the internet remain an unreliable source of fertility knowledge? Not necessarily, depending on what particular source is used. A study by Ford et al. performed in a group of Australian women showed that women who used phone apps to track their menstrual cycles knew more about fertility than those who did not (Ford et al., 2020). In this study, a regression tree relating to a knowledge test on fertility diet showed, at the second level, a relationship between the number of points scored in the knowledge test and whether the examined women chose the Internet as a source of knowledge. Women who used the Internet scored more points on the knowledge test than those who did not. This suggests that the Internet may indeed be a reliable source of information on fertility diet; the only concern that remains is whether all women of reproductive age can identify which Internet source is reliable and which is not.

When the results of both tests in this study were combined, the regression tree took into account another factor that divided the group into persons who were educated better or worse about reproductive health, i.e. age. The cut-off age was 26.5 years. It is possible that this is related to the average age of starting a family, although the average age of mothers giving birth in 2019, according to Eurostat statistics, was 29.7 years (Eurostat, 2021a), 
while the average age of getting married for the first time among women in 2019 was 27.7 years (Eurostat, 2021b). Due to the fact that preparation of a wedding ceremony in Poland usually takes about a year, the decision to start a family may lead to a greater interest in fertility and in obtaining knowledge in this area.

\section{Conclusions}

The obtained results revealed certain areas that have a significant impact on the level of knowledge about reproductive health, which may require additional education. The use of the regression trees method made it possible to determine relationships between the analysed data that were not fully visible after standard biostatistical analyses had been performed. The created trees can be useful in improving the process of dissemination of knowledge about reproductive health among women of childbearing age.

\section{R E F E R E N C E S}

Becker, G. F., Passos, E.P., \& Moulin, C. C. (2015). Short-term effects of a hypocaloric diet with low glycemic index and low glycemic load on body adiposity, metabolic variables, ghrelin, leptin, and pregnancy rate in overweight and obese infertile women: a randomized controlled trial. The American Journal of Clinical Nutrition, 102, 1365-1372

Breiman, L., Friedman, J., Olshen, R., \& Stone, C. (1984). Classification and Regression Trees. Wadsworth Publishing, CA.

Chawłowska, E., Lipiak, A., Krzysztoszek, J., Krupa, B., \& Staszewski, R. (2020). Reproductive Health Literacy and Fertility Awareness Among Polish Female Students. Frontiers in Public Health, 8(499). doi: 10.3389/fpubh.2020.00499

Eurostat, (2021a). Fertility indicators. Last update: 28-06-2021. Retrieved from: https://appsso.eurostat.ec.europa.eu/nui/show.do?dataset=demo_find\&lang $=\mathrm{en}$

Eurostat, (2021b). Marriage indicators. Last update: 07-06-2021. Retrieved from: https://appsso.eurostat.ec.europa.eu/nui/show.do?dataset=demo_nind\&lang $=\mathrm{en}$

Ford, E. A., Roman, S. D., Mc Laughlin, E. A., Beckett, E. L., \& Sutherland, J. M. (2020). The association between reproductive health smartphone applications and fertility knowledge of Australian women. BMC Womens Health, 20(1), 45. doi: 10.1186/s12905-020-00912-y 
Using Regression Trees to Find the Factors Influencing the Level of...

Gambineri, A., Laudisio, D., Marocco, C., Radellini, S., Colao, A., \& Savastano, S. (2019). Obesity Programs of nutrition, Education, Research and Assessment (OPERA) group. Female infertility: which role for obesity? International Journal of Obesity Supplements, 9(1), 65-72. doi: 10.1038/s41367-019-0009-1

Gatnar, E. (2001). Nieparametryczna metoda dyskryminacji i regresji. Warszawa: PWN.

Griffiths, A. G. F., Modinou, I., Heslop, C., Brand, C., Weatherill, A., Baker, K., Hughes, A. E., Lewis, J. et al. (2019). AccessLab: Workshops to broaden access to scientific research. PLOS Biology, 17(5), e3000258. doi: 10.1371/ journal.pbio.3000258

Hampton, K., \& Mazza, D. (2015). Fertility-awareness knowledge, attitudes and practices of women attending general practice. Australian Family Physician, 44(11), 840-845.

Ilic, D. (2010). The Role of the Internet on Patient Knowledge Management, Education, and Decision-Making. Telemedicine and e-Health, 16(6), 664-669.

Jahn, R., Müller, O., Nöst, S., \& Bozorgmehr, K. (2020). Public-private knowledge transfer and access to medicines: a systematic review and qualitative study of perceptions and roles of scientists involved in HPV vaccine research. Global Health, 16(22). doi: 10.1186/s12992-020-00552-9

Koronacki, J., \& Ćwik, J. (2005). Statystyczne systemy uczace się. Warszawa: Wydawnictwa Naukowo-Techniczne.

Maliszewska, A. M., Warska, A., Cendrowski, K., \& Sawicki, W. (2017). Inflammatory bowel disease and pregnancy. Ginekologia Polska, 88(7), 398-403. doi: 10.5603/GP.a2017.0074

Milewska, A. J., Jankowska, D., Cwalina, U., Citko, D., Więsak, T., Acacio, B., \& Milewski, R. (2016). Prediction of infertility treatment outcomes using classification trees. Studies in Logic, Grammar and Rhetoric, 47(60), 7-19. doi: $10.1515 /$ slgr-2016-0043.

Mu, Q., Hanson, L., Hoelzle, J., \& Fehring, R. J. (2019). Young Women's Knowledge About Fertility and Their Fertility Health Risk Factors. Journal of Obstetric, Gynecologic \& Neonatal Nursing, 48(2), 153-162.

Myszkowska-Raciak, J., Gurtatowska, A., Harton, A., \& Gajewska, D. (2013). Nutritional knowledge and selected aspects of the diet of pregnant women. Problemy Higieny i Epidemiologii, 94(3), 600-604.

Newton, V. L., Dickson, J., \& Hoggart, L. (2020). Young women's fertility knowledge: partial knowledge and implications for contraceptive risk-taking. $B M J$ Sexual \& Reproductive Health, 46(2), 147-151.

O'Hanlon, R., McSweeney, J., \& Stabler, S. (2020). Publishing habits and perceptions of open access publishing and public access amongst clinical and research fellows. Journal of the Medical Library Association, 1, 47-58. 
Skoracka, K., Ratajczak, A. E., Rychter, A. M., Dobrowolska, A., \& KrelaKaźmierczak, I. (2021). Female Fertility and the Nutritional Approach: The Most Essential Aspects. Advances in Nutrition, 12(6), 2372-2386. doi: 10.1093/advances/nmab068

Suliga, E., \& Głuszek, S. (2019). The relationship between diet, energy balance and fertility in men. International Journal for Vitamin and Nutrition Research, 90(5-6), 514-526.

Zawiejska, A., Ożegowska, K., \& Wender-Ożegowska, E. (2016). Choroby endokrynologiczne utrudniające zajście w ciążę. Ginekologia po dyplomie, 46(2), $147-151$. 